DOE/NV-367

UC-700

\title{
FRMAC-93 LESSONS LEARNED REPORT
}

\author{
Results of FRMAC-93 Exercise \\ Conducted at the Fort Calhoun Nuclear Power Plant \\ Omaha, Nebraska, June 30 - July 1, 1993
}

Compiled By

Kenneth C. Kerns

March 1994

Work Performed Under Contract No. DE-AC08-93NV11265

Prepared for the

United States Department of Energy

Nevada Operations Office

Prepared by

EG\&G Energy Measurements

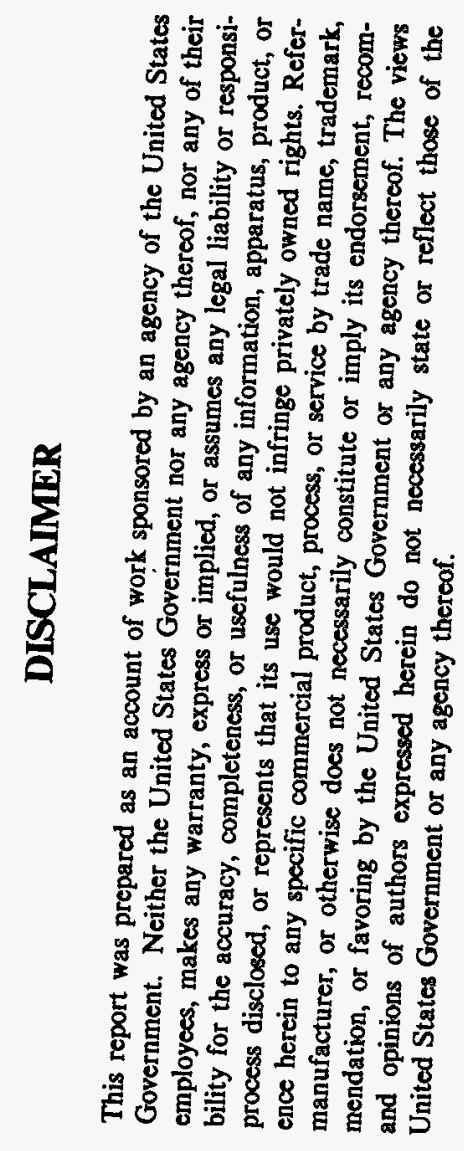




\section{DISCLAIMER}

Portions of this document may be illegible in electronic image products. Images are produced from the best available original document. 
Preface

Acknowledgements

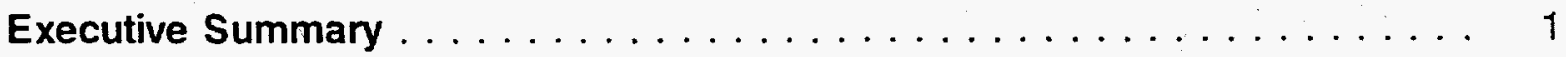

A. Day One .......................... 1

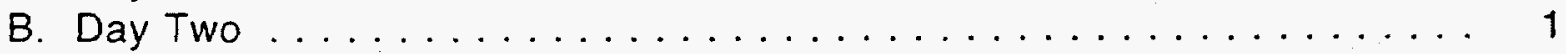

C. Day Three ............................ 1

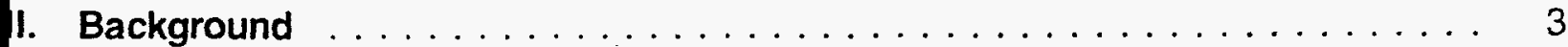

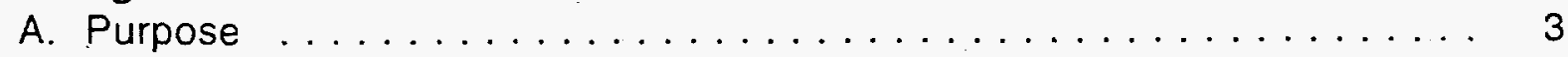

B. Scope ...................... 4

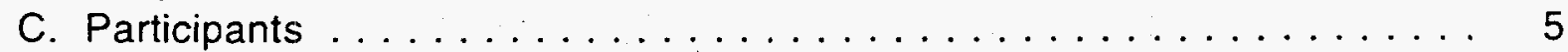

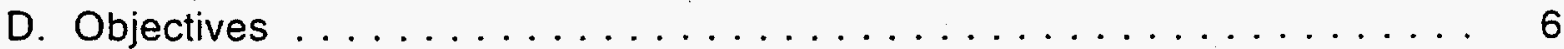

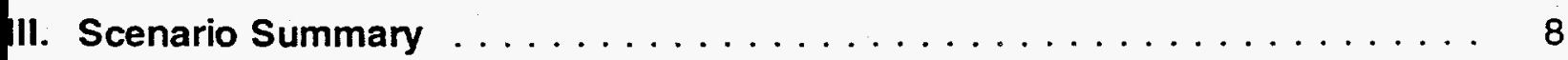

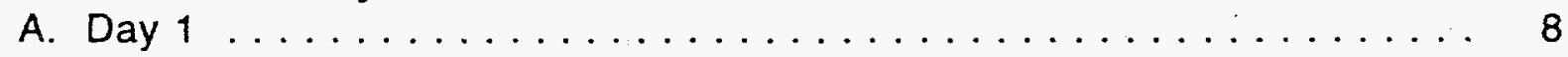

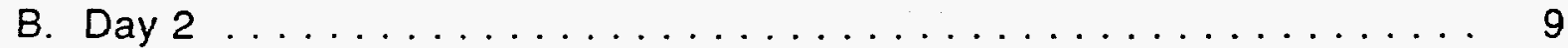

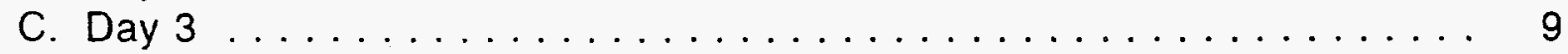

D. Plant Conditions . . . . . . . . . . . . . . . . . 10

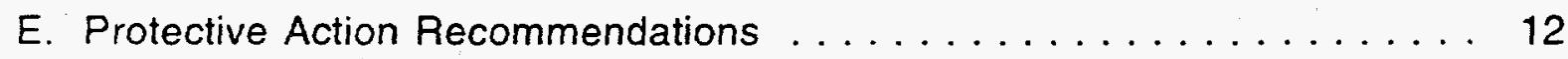

F. Radiological Activities . . . . . . . . . . . . . . . . . 12

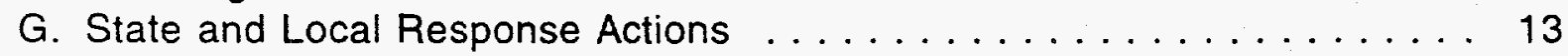

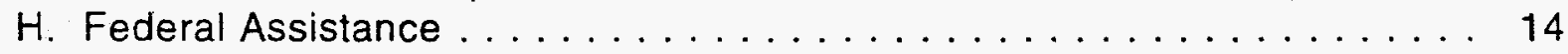

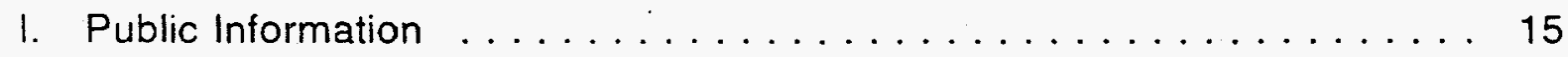

IV. Major Lessons Learned $\ldots \ldots \ldots \ldots \ldots \ldots \ldots \ldots \ldots \ldots$

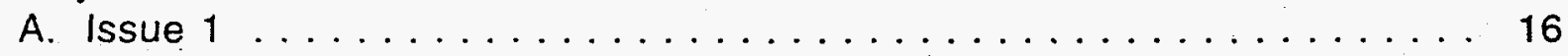

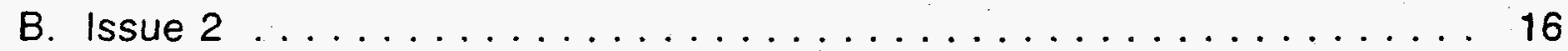

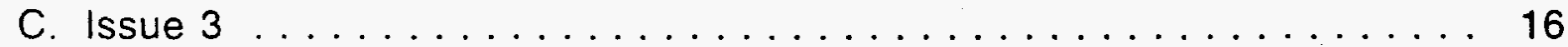

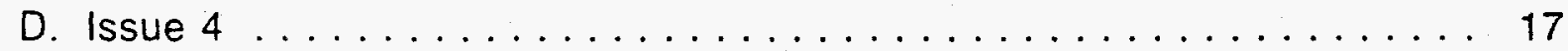

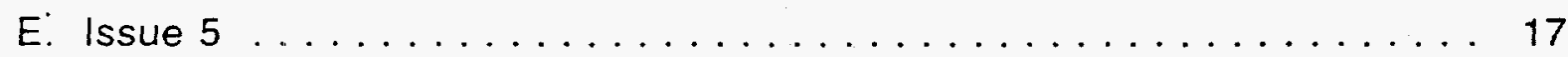

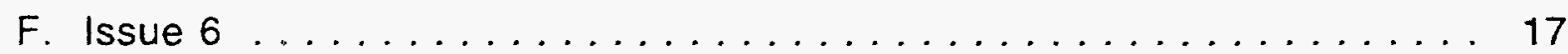

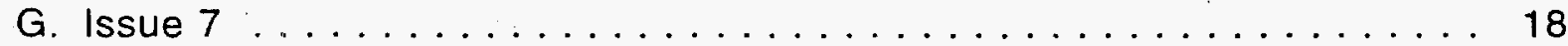

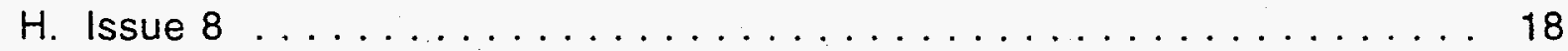

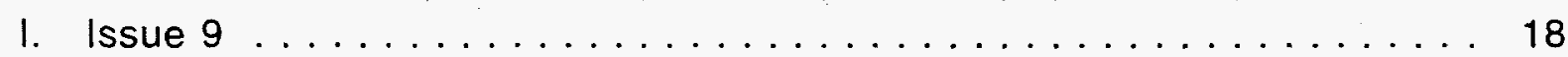

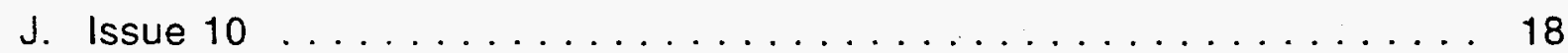

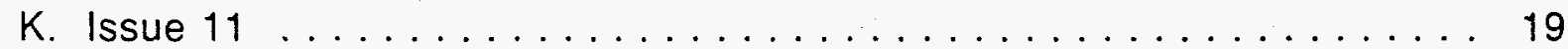

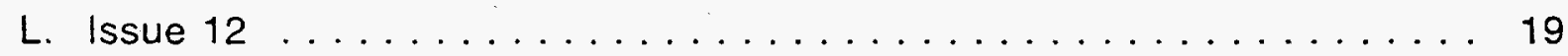

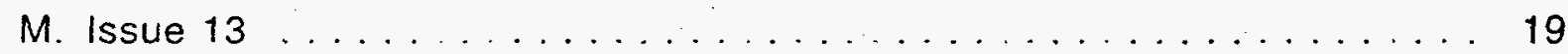

U.S. D.P.E. 


\section{Table of Contents \\ Continued}

\section{Pages}

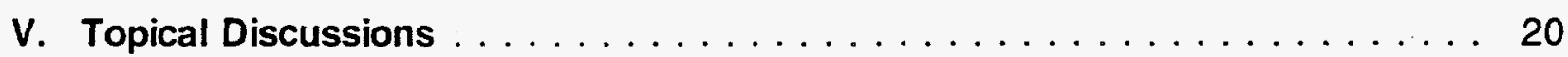
A. General Lessons Learned
B. Planning Lessons Learned . . . . . . . . . . . . . . . . . 20
C. Exercise Control Lessons Learned . . . . . . . . . . . . . . . . . 22
D. Scenario Development Lessons Learned . . . . . . . . . . . . . 23
E. Monitoring and Analysis (M\&A) Lessons Learned . . . . . . . . . . . . 24
F. Evaluation and Assessment (E\&A) Lessons Learned . . . . . . . . . . . 25
G. Data Management Lessons Learned . . . . . . . . . . . . . . . . . 26
H. Health and Safety (H\&S) Lessons Learned . . . . . . . . . . . 27
1. FRMAC Response Lessons Learned . . . . . . . . . . . . . . . 28
J. Training Lessons Learned . . . . . . . . . . . . . . . . . . 29
K. Organizational Changes .................... 30

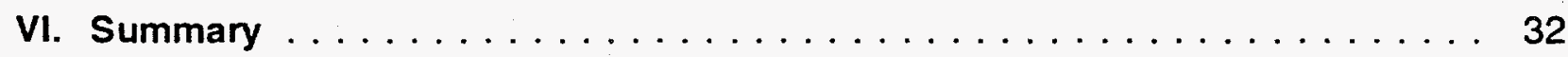

\section{Appendices}

Fort Calhoun Sector Map . . . . . . . . . . . . . . Appendix A List of Acronyms ...................... Appendix $B$

Summary of Critique Form Analysis . . . . . . . . . . . Appendix $C$

Draft DOE-EPA Transfer Agreement . . . . . . . . . . Appendix D 


\section{Preface}

This Lessons Learned Report is intended as a record of the FRMAC-93 Exercise. It is hot intended to place blame on any individual, organization, or agency. It should be egarded only as a source to capture the important lessons from FRMAC-93.

This document is a compilation of comments solicited from exercise planners and participants representing the utility, and several state and federal agencies. The many comments, criticisms, and recommendations were reviewed, and those with global application or major impact were considered for inclusion. All input received was considered valuable and are greatly appreciated.

-RMAC-93 was designed to exercise the Federal Radiological Monitoring and Assessment Center's support to the states; it was not a demonstration of response capabilities. There was a large risk of exposing weaknesses in the system to ensure that appropriate actions are taken in the future. Consequently, the benefits of improving the program will be realized.

We appreciate the efforts of the Omaha Public Power. District and the states of lowa and Nebraska volunteering to host this event. The U.S. Department of Energy and The Nuclear Regulatory Commission are to be commended for sponsoring an exercise of this magnitude and design. 


\section{Acknowledgements}

The Chairmen for the FRMAC-93 planning committee, would like to thank those members of the committee for their cooperation in the planning, conduct, and evaluation of the exercise. Without their dedicated efforts, the exercise could not have occurred. Specifically, Mr. Harry Borchert, Mr. Rick Semm, and their staff from the state of Nebraska; Mr Don Flater, Ms. Ellen Gordon, and their staff from the state of lowa; and finally Mr. Jay Clayton and Mr. Dick Andrews from the Omaha Public Power Districts' Fort Calhoun Power Station. The support provided by Mr. Bob Bissel and Ms. Dianne Wilson of FEMA Region VII was also substantial in this regard. In addition, Mr. Ken Kerns and Mr. Zolin Burson from the EG\&G Energy Measurements, Inc. in Las Vegas, Nevada, contributed substantially to the exercise and coordinated the production of this report. If any person or organization was inadvertently omitted, it was not by design.

Peter G. Mueller, Department of Energy, Nevada Operations Office

Eric D. Weinstein, U.S. Nuclear Regulatory Commission

Eugene F. Bates, U.S. Nuclear Regulatory Commission, Region IV 


\section{EXECUTIVE SUMMARY}

FRMAC-93 simulated a radiological accident at the Fort Calhoun Nuclear Power Plant, 25 miles north of Omaha, Nebraska. The exercise involved the states of lowa and Nebraska, the Nuclear Regulatory Commission (NRC) as the Lead Federal Agency (LFA), Federal Radiological Monitoring and Assessment Center (FRMAC), and several federal agencies with statutory responsibility for providing extensive assistance during any national emergency.

The U.S. Department of Energy (DOE) is the technical expert in areas of radiation assistance, assessments, and capabilities for the Federal Government. In the event of a major radiological emergency, DOE Nevada Operations Office (DOE/NV) provides emergency response assistance and support to the states and LFA through FRMAC. This assistance is designed to augment existing state resources in a coordinated effort to mitigate the consequences of a significant radiological accident.

FRMAC-93 was a major 2-day field exercise designed to determine the effectiveness, coordination, and operations of a DOE-managed FRMAC. Two more important objectives of the exercise were to ensure that appropriate priorities were established and assistance was provided to the states and LFA by the FRMAC. While encountering some unanticipated difficulties in the initial phases of operation, exercise objectives were fully met by the time the exercise concluded on Day 3.

A. DAY 1 OF THE EXERCISE. Involved the Fort Calhoun Power Station evaluated plume phase exercise. After the plume phase exercise terminated, meetings between the DOE Radiological Assistance Program (RAP) Team, the FRMAC Advance Party, and the states signaled the beginning of FRMAC-93.

B. DAY 2 OF THE EXERCISE. Involved the initial set up of the FRMAC. A weakness was identified in the FRMAC's ability to support state radiological decision makers. Data and resources were not provided to the states in a timely manner.

C. DAY 3 AND FINAL DAY OF THE EXERCISE. Demonstrated a better understanding of the needs and priorities of the states and LFA by FRMAC staff and a better appreciation by the states of the resources that can be provided by the FRMAC. The FRMAC management ensured that all major decisions involved the states and LFA. FRMAC management viewed key state radiological decision makers as part and parcel of a greater team effort. 
This report provides the lessons learned as a result of the exercise. From the onset, FRMAC-93 was considered by all as a "no-fault" exercise. It was not to be a demonstration of agency capabilities much like the Federal Field Exercises (FFEs). Participants were tasked to play the exercise as they would expect to respond in an actual event.

Exercises of the magnitude of FRMAC-93 are indeed rare. The exercise enabled planners and program managers to test new procedures and documentation, train new players, and allow the players to respond to technical situations in the manner they would expect in an actual emergency response. The intent of all exercises, including FRMAC-93, is to provide players and the opportunity to learn from errors, and apply those errors in improving FRMAC operations should the need arise during an actual deployment. State, LFA, and FRMAC managers are acutely aware of the mistakes made at FRMAC-93. Their experiences will provide them with the necessary tools should the need arise during an actual deployment.

The impact and lessons learned from FRMAC-93 provided the necessary impetus to make organizational and operational changes to the FRMAC program. Application of these changes were instituted in an exercise conducted at the DOE exercise located in Hanford, Washington, just 3 months later. The successful conduct of the "FREMONT" exercise demonstrated that implementing many of the lessons learned from FRMAC-93 proved to be highly advantageous to state personnel, as well as federal participants in a fully operational FRMAC. A report detailing lessons learned from "FREMONT" will be issued separately. 


\section{BACKGROUND}

\section{A. PURPOSE}

The purpose of the exercise was to create an environment in which a variety of organizations could carry out their planned response actions. Interactions between the various response elements provided an opportunity to verify the adequacy of existing plans and procedures. The resulting exercise critique and lessons learned report identify initiatives to refine and improve those plans and procedures.

FRMAC-93 was an exercise designed to examine the federal technical response to an accident at a nuclear power plant under actual field conditions, and to give players an opportunity to react to technical situations within the FRMAC as they would in an actual radiological emergency.

The first day of the exercise consisted of a Nuclear Regulatory Agency (NRA) and the Federal Emergency Management Agency (FEMA) evaluated plume phase exercise that had its own control plan and is not dealt with here. The licensee, states, and counties in the Emergency Planning Zone (EPZ) demonstrated the implementation of their emergency response plans. No actions during either the planning or conduct of Days 2 and 3 of FRMAC-93 interfered with the regulatory activities on Day 1.

Federal response activities began at the end of Day 1, following the conclusion of the evaluated exercise, with the arrival of the RAP Team and the FRMAC Advance Party. These advance teams interacted with state response organizations from Nebraska and lowa in addition to the NRC, as the LFA and the utility in the Emergency Operations Facility (EOF). On the two subsequent days, the emphasis involved issues such as ingestion, reentry, recovery, and return, and the use of federal technical assistance by state and local officials. Play ended on the third day with a tabletop session designed to facilitate the transition of FRMAC management from DOE to Environmental Protection Agency (EPA).

FRMAC-93 was a vehicle to test new procedures and to train new people within the FRMAC system. Because FRMAC exercises, such as this, are infrequent due to the resources required, the decision was made to place new people in key FRMAC positions to give them experience in a large scale emergency response. The more experienced FRMAC personnel served as coaches and were instructed to provide guidance to the players only when necessary. Several new procedures 
were evaluated during the exercise. The greatest benefit gained was the ability to test the procedures and identify areas that require modification.

The Protective Action Support Team (PAST) concept, as employed in the FRMAC, was tested for the first time during FRMAC-93. Federal agencies with responsibilities for protective actions, including EPA, Health and Human Services (HHS), and the United States Department of Agriculture (USDA), served in the PAST to assist the LFA in interpreting the Protective Action Guides (PAGs) for use by the states and locals. Additionally, they provided assistance to the states and LFA in relating FRMAC data to that guidance and assisted the LFA in developing a federal position on state and local Protective Action Recommendations (PARs). The concept and philosophy of the PAST are fundamentally sound and should be fully utilized by all potential LFAs.

\section{B. SCOPE}

FRMAC-93 portrayed events likely to occur in the technical response area centered on FRMAC operations based upon the coordinated efforts of federal, state, and local organizations and the utility in responding to a technical scenario. The emphasis was on issues such as ingestion, reentry, recovery, and return, and the use of federal technical FRMAC-based assistance for state and local officials. Federal agencies, with responsibilities described in the Federal Radiological Emergency Response Plan (FRERP), related to technical assistance participated throughout the 3-day exercise to the extent warranted by the scenario.

Nonradiological issues were not the focus of the two days of FRMAC-93. Nonradiological assistance was simulated through the simulation cells. A fully staffed FEMA Regional Operations Center (ROC) or Disaster Field Office (DFO) were not activated for this exercise. FEMA involvement included Regional FEMA representatives within the FRMAC and an exercise simulation cell simulating actions anticipated by the National and Regional offices. 
C. PARTICIPANTS

Actual Participants

NRC FRMAC Site Team

Protective Action Support Team (EPA,HHS,USDA, NRC)

FRMAC Staff (DOE AND EPA)

DOE Chicago Operations Office (DOE/CH)

DOE Nevada Operations Office (DOE/NV)

DOE Brookhaven Area Office (DOE/BAO)

DOE Headquarters (DOE/HQ)

EPA Office of Research and Development

EPA Office of Radiation and Indoor Air

EPA Region VII

FEMA Region VII

National Oceanic and Atmospheric Administration (NOAA)

Nebraska Radiation Health

lowa Radiation Health

lowa Emergency Management Division

Omaha Public Power District FRMAC Representative

Los Alamos National Laboratory

Argonne National Laboratory

Lawrence Livermore National Laboratory (LLNL)

Brookhaven National Laboratory

Oak Ridge National Laboratory

EG\&G Energy Measurements, Inc.

Reynolds Electrical \& Engineering Co., Inc.

Simulated Participants

NRC HQ Operations Center

NRC Region IV Base Team

NRC Region I

NRC Site Team (other than those in FRMAC)

FEMA HQ and DFO

DOE/HQ Emergency Operations Center (EOC)

DOE Chicago EOC

DOE Nevada EOC

Omaha Public Power District (OPPD) Emergency Facilities

Nebraska Civil Defense and EOC

lowa EOC 


\section{Risk Counties}

Nebraska: Washington and Douglas

lowa: Harrison and Pottawattamie

\section{OBJECTIVES}

One measure of the success of an exercise is how well the stated objectives were met. The FRMAC-93 objectives were designed to test the capabilities of the FRMAC to provide assistance to the states and to evaluate the effectiveness of new procedures and assets. The exercise objectives were to evaluate capabilities not to demonstrate them. All exercise objectives were successfully met.

The broadly stated objectives for the FRMAC-93 exercise were:

1. To verify the guidance to the state and other federal agencies, functional procedures, analysis tools, and training in the following areas:

a. Providing federal information on actual and projected radiological conditions.

b. Developing and presenting the federal position on protective actions to the state(s).

2. To verify the adequacy of concepts, procedures, and training:

a. Developed by DOE to support a FRMAC.

b. Used by EPA, USDA, and HHS in support of the NRC as LFA.

c. For NRC in its role as LFA in relation to the FRMAC.

3. To utilize global positioning systems (GPS) for field teams.

4. To verify plans for the coordination and deployment of a full NRC site team.

5. For DOE to support the state, local government, and LFA with off-site monitoring and assessment capability.

6. For DOE to prioritize environmental monitoring and data assessment to accommodate state requirements. 
7. To exercise the capability of FRMAC to provide technical support for ingestion pathway and recovery issues and concerns as requested by the state and LFA.

8. To verify the integration of the geographic information system (GIS) and various data sets into FRMAC operations.

9. To ensure that all environmental data and assessment results are available by FRMAC to key decision makers.

10. To verify the integration of NRC organization, NRC PAST, and state field teams into FRMAC operations.

11. To exercise FRMAC management transfer from DOE to EPA.

12. To exercise all elements of FRMAC for data gathering, assessments, and subsequent transfer of that information to appropriate decision makers.

13. To integrate the Atmospheric Release Advisory Capability (ARAC) projections, Aerial Measuring System (AMS), RAP, and state radiological data sets into FRMAC database and GIS.

14. To exercise RAP, FRMAC Advance Party, and full party integration.

15. To test liaison and interface with state, utility, and LFA.

16. To exercise the coordination role of FEMA in the following areas:

a. FEMA Liaison Officer within the FRMAC.

b. Handling requests for federal assistance from states on implementing protective actions concerning off-site radiological emergencies. 


\section{SCENARIO SUMMARY}

FRMAC-93 simulated a major radiological emergency at the Fort Calhoun Nuclear Power Station, located near Fort Calhoun, Nebraska. Simulated operating conditions in the emergency scenario threatened the integrity of the station.

Exercise planners used the EPA PAG Manual' as the basis for designing off-site radiation and projected dose levels requiring protective actions from long-term exposure to deposited radioactive materials. The EPA and HHS PAG were not exceeded beyond 10 miles. The Nebraska and lowa State and local emergency response plans were used to determine the need for protective actions for plume and ingestion exposure pathways during the plume phase and were the basis for subsequent action on days 2 and 3 to the degree possible.

The following activities which were demonstrated in response to the scenario:

\section{A. FIRST DAY OF THE EXERCISE (SCENARIO DAY 1) EVALUATED}

1. Initiation of a power plant emergency which creates significant on-site problems and a large off-site release.

2. Notification of emergency response organizations.

3. Activation of state, local, licensee, and federal response plans.

4. Decision making on protective actions by all involved parties.

5. Deployment of a FEMA State Liaison to state EOCs.

6. Activation of the FEMA ROC.

7. Deployment and on-scene operation of state, local, licensee, and federal response efforts.

8. Radiation monitoring off-site.

9. Notification of the public.

'Manual of Protective Action Guides and Protective Actions for Nuclear Incidents, EPA400R-92-(0)1. U.S.Environmental Protection Agency, Washington(1992) 
10. Notification of the Congress.

11. Notification of the White House.

12. Response to public and media concerns about the effects of off-site radioactive contamination and related implications.

13. Reports of the on-site situation.

14. Requests for federal assistance to RAP and FRMAC.

15. Initial RAP response and coordination with states.

16. FRMAC Advance Party.

B. SECOND DAY OF THE EXERCISE (SCENARIO DAY 2)-(FRMAC-93)

1. Off-site radiological field monitoring, sample collection, and analysis.

2. Establishment of the restricted area.

3. Establishment of the FRMAC.

4. Assessment of radiological data and preparation of data presentations.

5. Consideration of reentry concerns.

6. Consideration of further public protective actions, including ingestion exposure pathway concerns.

7. Continuing reports of the on-site situation.

8. Provision of federal assistance to states.

9. Needs assessment of accident recovery resources.

C. THIRD DAY OF THE EXERCISE (SCENARIO DAY)

1. Determination of return or relocation of the evacuated public and recovery of the affected area. 
2. Determination of appropriate actions relative to contaminated food, land, and property.

3. Assessment of the dose and health effects to the public.

4. Consideration of decontamination procedures, both immediate and long-term.

5. Consideration of transfer of FRMAC management responsibility to EPA from DOE.

6. What was NOT exercised on days 2 and 3 . (All of the following were accommodated through the control cell.)

a. Public Affairs/Joint Information Center.

b. Disaster Field Office.

c. Insurance reimbursement (American Nuclear Insurers).

7. Stafford Act implementation.

8. Federal Response Plan.

The following information describes the activities and events which occurred from 6 a.m., June 29, 1993, until 8:30 a.m., June 30, 1993. This information was given to exercise participants as reference material concerning events leading to the start of the FRMAC-93 exercise at Fort Calhoun.

\section{PLANT CONDITIONS}

At approximately 6:30 a.m., June 29, 1993, the Fort Calhoun Nuclear Power Station experienced a simulated sequence of events leading to the release of monitored and unmonitored radionuclides to the environment and the implementation of its Emergency Plan. An explosion, caused by a hostile intruder, resulted in a loss of off-site power. From this, the licensee declared a Site Area Emergency. It was later determined that the intruder had been killed as a result of the explosion. Law enforcement determined that he was acting alone. 
The loss of off-site electrical power was accompanied by a loss of reactor pressure boundary integrity which was complicated by an inability to provide adequate safety injection to the core. This resulted in the core being uncovered and damage to the reactor fuel. Pressure in the containment rose due to the release of reactor coolant and the unavailability of containment sprays. Containment cooling was adequate to prevent any excessive challenges to the containment structure. Several small monitored and filtered releases occurred during the morning of the 29th; however, the failure of a penetration seal at approximately noon allowed a substantial release of unfiltered radioactive materials (primarily noble gases) to the environment. The licensee quickly isolated the leak and established stable core conditions.

From noon until approximately 10 p.m., the licensee kept the reactor core covered using the recirculation mode for core cooling. In the recirculation mode, reactor coolant, which leaks from the core and accumulates in the containment slump, is pumped to the auxiliary building, where it is cooled in a heat exchanger, and then reinjected into the core. This mode can be used indefinitely for purposes of long-term core cooling. Throughout this period, radiation levels in containment were approximately $10,000 \mathrm{R} / \mathrm{hr}$, indicating large amounts of radioactive material in the containment and high radiation levels in the auxiliary building. Small releases from the auxiliary building developed as a result of leaks in the pipes carrying the recirculated water from the containment slump.

At approximately 10 p.m., there were indications that the pumps drawing water from the containment slump were losing suction. It was hypothesized that there was clogging in the suction path as a result of debris in the containment slump. The plant operators initiated a process of "jogging" the pumps on and off in an attempt to clear the clog as opposed to continuing to run the pumps without sufficient net positive suction head. This resulted in the core being uncovered for a second time at approximately 11 p.m.

At midnight, the clog was cleared and the recirculation mode was reestablished. The core was recovered at this time. However, severe damage to the fuel occurred during the period the core was uncovered. Large amounts of radioactive gases were released to the containment-containment radiation levels approached $50,000 \mathrm{R} / \mathrm{hr}$. In addition, the damage to the Zircaloy fuel cladding resulted in the generation of large quantities of hydrogen (indicated levels in containment exceeding 7 percent). 
The systems used to cool the containment during the accident were still not available and, as a result, the containment pressure increased. At approximately 3:30 a.m., central daylight time radiation levels $1 / 2$ mile from the plant increased significantly (between 80 to $300 \mathrm{mR} / \mathrm{hr}$ ), indicating a leak to the environment. The leak was the result of a purge valve in the containment failing to open as a result of a hydrogen burn. By 4:45 a.m., the leak had been stopped by the licensee.

Calculations (by the NRC) and utility field monitoring results indicated that the release was consistent with a release of a substantial fraction (e.g., 1/10 to 1/50) of the fission products in the containment. This type of release would contain large amounts of iodine, cesium, and other fission products. Containment sprays and cooling were established by 5 a.m., which greatly reduced the threat of another major release. Small releases continued from the plant auxiliary building due to the degassing of highly contaminated coolant. This coolant was being recirculated through the auxiliary building as part of the core cooling process and these types of releases were expected for some time.

\section{E. PROTECTIVE ACTION RECOMMENDATIONS}

Off-site PARs issued June 29, 1993, remained in effect for sheltering of farm animals within the 10 mile EPZ and placing them on stored feed. Portions of Washington County, Nebraska, and Harrison County, lowa, were evacuated. Specific protective actions initially decided were the evacuation of the area within a 5 mile radius of the plant. The utility recommended that the remainder of the EPZ be sheltered; this recommendation was considered but not implemented by the states.

As the plant conditions deteriorated and as the wind direction shifted, the evacuation decision was sequentially expanded at about noon on June 29 to include the areas within 5-10 miles of the plant. In Nebraska, Sectors P, Q, R, and $A$ were evacuated (see Appendix A). In lowa, Sectors $R, A, B, C$, and D were evacuated. This includes the towns of Blair and Fort Calhoun in Nebraska and Modale and Missouri Valley in lowa. Approximately 8,900 people in Nebraska and 4,000 people in lowa were evacuated.

\section{F. RADIOLOGICAL ACTIVITIES}

The last of the plume appeared to have dissipated. The field teams reported higher levels of radiation than normal background throughout the northern portion of the EPZ within a 10 mile radius. Only representative readings from a few 
locations were available. The deposition appeared to agree with the early projections.

Eight two-person environmental monitoring teams worked throughout the night monitoring the plume passage to the west and east of the plant. The teams were composed of personnel from OPPD, the states of Nebraska and lowa, and DOE RAP Region V (Chicago). The EOF personnel positioned the field teams based on the wind direction to ensure that the plume time of arrival, duration, and magnitude were documented. Several air samples were taken by the teams during the plume passage. Other samples, such as soil, crops, water, and milk were not collected.

The field monitoring forms were given to the Monitoring and Analysis (M\&A) Division in FRMAC. The air sample cartridges were given to the mobile labs for analysis.

\section{G. STATE AND LOCAL RESPONSE ACTIONS}

1. The lowa and Nebraska State EOCs and Washington County, Nebraska; and Harrison and Pottawattamie County, lowa; EOCs were fully activated and staffed.

2. Support personnel were mobilized by the states and counties. Both states and the utility activated field monitoring teams. The teams took appropriate measurements to attempt to characterize the deposition.

3. All appropriate PARs had been implemented.

4. Appropriate access control stations were established for the evacuated and sheltered areas. They reported no major problems.

5. Students in Blair, Nebraska Jr. and Sr. high schools, were in summer session and were evacuated. Special facility patients in the Crowell Memorial Home, Good Shepherd Home, and Memorial Hospital, all located in Blair, Nebraska, were evacuated to the hospital and nursing homes in Fremont, Nebraska. Special facilities within Missouri Valley, lowa, were evacuated as follows: patients in Longview Home to the Rose Vista Home in Woodbine, lowa; patients in Community Memorial Hospital to Crawford County Memorial Hospital in Denison, lowa; and elderly residents from the Culivan Heights Senior Citizens Residence also to Denison, lowa. 
6. DeSoto Bend National Wildlife Refuge in Nebraska and lowa and Wilson Island State Park in lowa were evacuated and closed.

7. Registration and monitoring centers for the public were opened in Crawford County, lowa (Denison High School); and Sarpy and Dodge County, Nebraska (Fremont Sr. High School and First Baptist Church). Congregate care centers were activated and staffed for persons requiring temporary lodging and care.

8. State forward EOCs were established for Nebraska at the EOF and lowa at the Harrison County EOC.

9. The state requested federal assistance in characterizing the radiological deposition from DOE and decided to collocate its Field Monitoring and Radiological decision making functions to the FRMAC. They also requested assistance for unanticipated nontechnical needs from FEMA.

\section{H. FEDERAL ASSISTANCE}

NRC received the initial emergency classification from the licensee early on June 29 as per procedure. NRC notified the other federal agencies and dispatched a team to the Site by midday. The team was placed under the leadership of the Director of Site Operations. NRC was the LFA for this event. NRC coordinated with DOE to send a RAP and FRMAC Advance Team to the site for radiological assistance. The initial meeting of these organizations and the states and utility took place in the evening of June 29 in the licensee's EOF. State priorities for assistance were addressed. NRC worked with FEMA for coordination of nonradiological assistance for the states and locals. FEMA Region VII ROC was activated. The FEMA Emergency Response Team was activated and deployed to the Omaha area. NRC and FEMA state liaisons were deployed to the lowa EOC in Des Moines, lowa, and Nebraska, EOC in Lincoln, Nebraska and the forward EOCs.

lowa and Nebraska requested assistance through FEMA on June 29 at 11 a.m. A Presidential "Emergency" declaration was made by the President on June 30, at 1 a.m., at the request of the Governors of the two states. A preliminary damage assessment was waived due to the nature of the event. A DFO and FRMAC were established and activated by 8:30 a.m., on June 30 . Representatives of NRC, FEMA, USDA, EPA, and DOE and other federal agencies reported to these facilities. The DFO was located at the Auditorium

14 U.S. DEPAFH DOE/NY TECHNGCA IMFORMAION RESOURCE GEITER Las Vegas, 
Building of AK-SAR-BEN in Omaha, Nebraska. The FRMAC was located in the National Guard Armory, 72nd Street and Abbott Drive, Omaha, Nebraska.

The Acting Regional Director of FEMA Region VII was appointed by the President as Federal Coordinating Officer (FCO) to coordinate with state and local officials concerning off-site nontechnical response actions to assist state/local jurisdictions. The FCO worked with the Nebraska and lowa State Coordinating Officers in the DFO. The FRMAC Director operated out of the FRMAC where coordination of the technical response actions occurred.

The Federal Bureau of Investigation responded to the site due to the presence of an intruder early on and was in charge of the law enforcement aspects of the response. They worked closely with state and local law enforcement personnel. It was determined that the law enforcement threat to the facility no longer existed.

I. PUBLIC INFORMATION. The Joint Information Center (JIC) [Media Release Center] was activated at the declaration of the Site Area Emergency on June 29, 1993. State and utility public information officers responded to inquiries from the media at the JIC, which was located at the DFO. NRC, as LFA, represented the Federal Government in the JIC. FEMA was also represented there. Other federal agencies sent public affairs staff to the JIC to represent their agency interests there. 


\section{MAJOR LESSONS LEARNED}

A. ISSUE 1. Because the states are responsible for protective actions, it is imperative that the FRMAC management and other federal agency representatives initiate early contact with their state counterparts to establish the proper working relationships. This relationship was not in effect early in FRMAC-93.

1. Recommendation. FRMAC Advance Party procedures and checklists should be developed as a guide during the initial meeting with state representatives. A DOE state outreach program should be developed in coordination with the NRC outreach program to include a greater emphasis on FRMAC structure, policies, and procedures.

2. Action. DOE/NV, NRC

B. ISSUE 2. An initial monitoring and sampling plan was developed with input from one state representative before the field monitoring teams were dispatched from the FRMAC. The major decision makers for the states were not involved in this planning. The plan should have been developed at the initial advance party meeting with the state decision makers to elevate the importance of the plan, to get the states buy-in, and to ensure a cooperative effort. In addition to the state representatives, this monitoring plan should be developed in consultation with the Evaluation and Assessment (E\&A) Manager and the Senior Scientific Advisor.

1. Recommendation. The monitoring and sampling plan should be developed with state and other federal input during the advance party meeting. A generic monitoring and sampling plan may be used to direct field monitoring and sampling activities until well-defined goals and priorities are developed with the state and LFA, and FRMAC.

\section{Action. DOE/NV, FRMAC M\&A Manager}

C. ISSUE 3. The FRMAC Director and his key staff were often not available to meet with the state and LFA representatives. When the Director called meetings with the division group managers, the group operations became greatly impaired and no decision makers were left on the FRMAC floor to address the concerns and questions of the states. 
1. Recommendation. Group managers within the FRMAC need knowledgeable deputies to assume responsibility for the continuation of operations. State and LFA representatives should be included in all FRMAC management meetings.

2. Action. DOE/NV

D. ISSUE 4. FRMAC field and laboratory raw data were not immediately distributed to the states and LFA. Early field monitoring results may be all that the states have on which to base protective actions.

1. Recommendation. Data collected by the FRMAC field teams and laboratories must have a wide distribution within the FRMAC, especially to the state and LFA representatives. Only cursory quality checks should be applied before distribution.

\section{Action. DOE/NV}

E. ISSUE 5. Several predictive models were used in the FRMAC, but there was no attempt to compare the model results. Decisions, such as where to dispatch field and aerial monitoring teams, were made based on the results of one model. This model used the meteorological data in a way that differed from how the exercise planners and the other models used the same data. Because the differences were not resolved, this resulted in a poor use of resources.

1. Recommendation. The results of all available models will be considered when developing the field sampling plan and protective actions. The predictions manager should be independent of any modeling capability. Predictive models cannot replace empirical field data and should be only used to help guide the placement of field teams.

\section{Action. DOE/NV FRMAC E\&A Predictions Manager}

F. ISSUE 6. Training must become a routine part of any emergency response system. The lack of familiarization with procedures and equipment in the FRMAC was apparent at all levels. A large-scale exercise every few years is not sufficient to ensure that adequately trained personnel will be available for a real event.

1. Recommendation. All levels of the response organizations should be frequently trained and exercised.

2. Action. DOE/NV. 
G. ISSUE 7. FRMAC personnel were not given periodic briefings. Although information was given to the key managers during meetings, the information was not always passed along. Field teams did not receive updates on weather or radiological conditions.

1. Recommendation. Brief (10-15 min.) all-hands meetings should be held periodically to give updates on the status of the plant conditions, goals, and priorities for the FRMAC, status of the response, health and safety considerations, and any other important information.

2. Action. DOE/NV FRMAC Director.

H. ISSUE 8. The FRMAC placed too much reliance on computer technology for data retrieval and display. Dependence on the automated systems impaired the FRMAC's ability to complete assessments when the systems malfunctioned.

1. Recommendation. Procedures need to be identified which will allow the primary route of data analysis to shift from computer technology to manual calculations and plotting when technological problems occur. A bypass system for critical data will ensure that data are immediately assessed without delay.

\section{Action. DOE/NV.}

I. ISSUE 9. The request tracking system and the data/information flow did not work efficiently. Too many steps, checks, and balances in the FRMAC procedures contributed to the FRMAC being ineffective on Day 2.

1. Recommendation. The request tracking system is a necessary part of the FRMAC; the tracking system should be simplified and managers trained to use the system efficiently. The data/information flow must be revised to remove any bottlenecks which may cause delays within the FRMAC. Priority data must be identified and distributed without delay.

\section{Action. DOE/NV.}

J. ISSUE 10. The physical positioning of the sample control area, hotline, and mobile laboratories was based on a first-come, first-serve basis. The floorplan developed for FRMAC-93 was not followed which resulted in poor use of space and an unrealistic placement of assets. 
1. Recommendation. Assets should be positioned based on a master plan which makes the best use of the space available. Caution must be used to ensure that laboratories are not positioned too close to sample processing and storage areas, which could cause elevated background readings.

2. Action. DOE/NV.

K. ISSUE 11. The inclusion of the PAST in the FRMAC proved to be a valuable asset for the LFA and the state technical decision makers. Federal PARS were quickly interpreted and modified based on incoming monitoring results. The PAST can be a great asset to all the potential LFAs, especially those who do not have the technical capability to interpret and develop positions on PARS.

1. Recommendation. The formal adoption of the concept of a PAST in the FRMAC should be vigorously pursued.

2. Action. NRC, EPA, USDA, and HHS.

L. ISSUE 12. FEMA has the responsibility for performing the risk assessments which would be used in recommending an Emergency Declaration by the President. This task was made easier by having direct access the FRMAC to data and assessments.

1. Recommendation. An expanded, formalized role for FEMA in the FRMAC should be considered.

2. Action. FEMA Region VII, FEMA Headquarters

M. ISSUE 13. The DOE to EPA FRMAC transition meeting and draft transfer procedures were successful in identifying those issues that need to be considered prior to a formal transition.

1. Recommendation. The draft transfer procedures should be formalized and distributed to the states for their information.

2. Action. EPA, DOE/NV. 


\section{TOPICAL DISCUSSIONS}

\section{A. GENERAL LESSONS LEARNED}

1. Display boards need to be placed in a central area. Information beneficial to all FRMAC participants such as the latest results and products depicting predicted cloud deposition, meteorological forecasts, general information for all participants (e.g., next all-hands meeting, floor layout), and other critical data should be posted. All displayed data must be current.

2. The FRMAC Advance Party interface with the state(s), LFA, and RAP appeared to labor at times. DOE/FRMAC should develop a comprehensive checklist to assist in the formulation of a working plan with the LFA, states, and RAP teams. In addition, the RAP and FRMAC Advance Party should meet privately for a short period of time prior to meeting with state and LFA representatives. The RAP Team captain should meet the Advance Party at the arrival point.

3. FRMAC plans, procedures, and training always center around the fully functioning FRMAC, but this and many exercises focused on the startup process. During an actual response, there will be a gradual buildup of FRMAC assets and resources. Much of the groundwork of developing relations with states, creating monitoring and sampling plans, and setting up the FRMAC would occur over a period of time. This exercise assumed that these events had taken place but did not provide the necessary products from these events.

4. The FRMAC is evolving from a federal center to a joint federal/state center. There is the possibility of a strong state presence in the FRMAC depending on the nature and location of the accident. The FRMAC must be prepared to incorporate additional state personnel in its operation, but not be dependent on such personnel.

\section{B. PLANNING LESSONS LEARNED}

1. Introduction. The exercise planning was conducted in only five months. The planning structure was loosely based on FFE-3 planning and was broken into one planning committee and three workgroups. The EXPLAN, Controller Handbook, and many injects were also loosely based on FFE-3 work which was modified to accommodate FRMAC-93 requirements. The NRC estimates that it took an equivalent of 1.3 full time employees to accomplish the exercise 
planning and participation for NRC planners and players. Approximately 400 people participated in FRMAC-93.

2. Throughout the exercise differentiating between players, observers, controllers, and visitors was difficult. Although the controllers wore red hats, their job functions were not identified. Name tags should have been worn by everyone in the FRMAC with their name, organization, and job function specified. Most FRMAC personnel were badged, but this did not appear to be sufficient to "advertise" who you were and what you did. Likewise, the different functional areas should have been labeled with large overhead signs so that players could easily locate the specific areas. These are simple fixes to a major communication problem.

3. Some felt that the observers and the visitor tours interfered with the play. Because this type of event does not occur frequently, observers were encouraged to get the most mileage out of the exercise. The plan to identify the areas where the visitors and observers had access was changed during the exercise setup because of the possible safety hazard. This allowed the visitors and observers to have full access to all areas of the FRMAC and resulted in overcrowding of work areas. The problem should have been foreseen and prevented by the planning stuff. Future exercise planners need to discourage the presence of large masses of nonplayers when possible, or as a minimum have supervised, small groups.

4. The free-play format for an exercise is a very powerful tool for evaluating methods and procedures. Key decisions were made based on the players evaluation by a situation, and not on the fear of errors which would be recorded by the evaluators. The first day of the exercise exhibited the "growing pains" that may be expected in a major response as procedures are implemented and roles are understood.

5. Future exercises must allow sufficient time for full interaction between the states, LFA, RAP, and the FRMAC Advance Party.

6. Finally, there were problems associated with piggy-backing a large-scale exercise, such as FRMAC-93 or an FFE, with an evaluated exercise. Future large-scale exercises should be independent of other exercises--especially evaluated ones. 


\section{EXERCISE CONTROL LESSONS LEARNED}

1. Introduction. Generally, the control plan was executed as conceived with the exception that the Master Control Group (MCG) was not available in the Exercise Control Cell except when special meetings were called. Therefore, the Event tracking operation changed. The event tracking group produced a good summary of ongoing exercise events that will serve as a reconstruction of exercise activities. It was not necessary, however, to have the MCG available in the exercise control cell all of the time. What became necessary was that an event-tracking person act as liaison to the controllers on the floor to assure that each controller provided feedback to the event trackers to allow for a complete picture of exercise activities.

2. More controller training was desirable based upon the experience of the control staff. Some controllers lacked the appropriate background and needed more detailed instructions which impacted on the limited time available for training. In order to minimize the cost of the exercise, training was scheduled during the week of the exercise, thus competing with other activities and not allowing enough time for controllers to digest the information before the start of the exercise. Several field team controllers did not have adequate health physics background to effectively provide radiological data to the players. Some field team members could serve as "trusted agents"; they would be privileged to control information while still filling the role of a player.

3. The simulation cells were generally too large and the staff was generally of too high a level to support the needed efforts on the floor of the FRMAC. It is important to reiterate that the nontechnical activities such as public affairs and state decision making were not being exercised, and this was a source of some frustration on the part of some simulation cell controllers.

4. Some control staff introduced unscheduled injects which created some confusion and difficulty on the part of the event tracking group to assure that the exercise flowed according to plan. Impromptu injects were introduced to exercise specific capabilities in the FRMAC, but these injects were not planned or approved by the MCG. 


\section{SCENARIO DEVELOPMENT LESSONS LEARNED}

1. Introduction. Because Days 2 and 3 of FRMAC-93 could not interfere with the graded plume phase exercise (Day 1), the scenario developers for both portions of the exercise had to work independently. This caused a few minor problems in trying to ensure continuity. To give the players a running start, a very large packet was distributed to the players at the beginning of Day 2 which represented the work that would have been conducted during the night. But insufficient time was given to the players to digest the information in the scenario package before the exercise was in full play.

2. Some feel that not enough data were provided to adequately represent what would have been accomplished during the night. Others believe that this large amount of data is not realistic and should not be "dumped" on the players all at once. The size of the scenario break message is probably not as important as the amount of time available to read and submit it through normal channels. The break message should be given to the players to closely study before the exercise begins so that they will not be at a disadvantage.

3. Scenario development was generally good. However, better control over the information made available to the players needs to be assured. A critical piece of information regarding the evacuation of certain sectors appeared in the scenario information package given to the players. The information was wrong and much time was wasted in sorting it out.

4. Notionalized weather information for the evening of Day 1 was based on actual historical weather data for the surrounding area and was provided to organizations bringing deposition modeling capabilities to the FRMAC. One predictive model used only the Fort Calhoun plant meteorological data for their predictions instead of the recommended area wide meteorological data which was used for the scenario development. This caused their projections to differ greatly from those of other models. Because the players had the same data but did not use the data in the same manner, the problem is procedural in nature.

5. An AMS helicopter provided exercise support through the use of a real-time exercise data generator. The data provided by the AMS proved to be the most effective means of obtaining the "big picture." Because the helicopter collected the data in real time, it added an element of realism that was absent in previous exercises. The use of the data generator and AMS aircraft will be beneficial to future exercises and training events. 


\section{E. M\&A LESSONS LEARNED}

1. Introduction. The first few hours of the FRMAC portion of the exercise proved to set the pace for the entire second day. There was a big rush to deploy the field monitoring teams to begin the monitoring functions. An important first step in the deployment of any emergency response element is developing a plan. This important step must be written into the FRMAC field monitoring plan to ensure that the field assets are used efficiently. Each field team should be briefed on the overall situation and what their specific role will be. The necessity for deploying field teams expeditiously must be balanced with developing a joint monitoring plan.

2. The communications between the FRMAC and the field teams were hindered by the large numbers of field teams on a single radio channel. When a controller inject involving an injured field team member was introduced over the radio, all other communications on the channel were halted and resulted in the delay of information transfer. Improper radio protocol also caused transmission delays while messages were repeated. The M\&A Working Group must evaluate the appropriateness of the current field communication procedures and implement the necessary changes.

3. The field teams encountered problems associated with the GPS units. This can be corrected with adequate training and written procedures.

4. Inadequate maps for the field teams continue to be a problem throughout. Knowledgeable state or local guides need to be considered for dispatch with the field teams to expedite finding locations for monitoring and sampling, in addition to adequate maps.

5. Three federal mobile laboratories participated at FRMAC-93. There were significant differences in capabilities and through-put of each laboratory which required $M \& A$ to carefully evaluate the abilities of each laboratory and plan accordingly. Only the EPA brought a dedicated sample preparation facility, which was quickly overwhelmed when tasked with preparation of all the field samples. This facility was designed to support the EPA mobile laboratory and quickly ran out of sample geometries and preparation equipment. Every mobile lab should have its own sample preparation capability, but the FRMAC must be able to provide sample preparation in the absence of the capability. A DOE sample preparation facility should be designed, built, and equipped for FRMAC use. 
6. A sample priority system was established by M\&A personnel and was used in the laboratories until the sample load became too great in sample preparation. This system broke down because controller information was not presented in the same fashion as would have been generated by the labs.

7. Although an exercise artificiality, the Omaha National Guard vehicles occupied the same compound as the mobile labs. In a real response, this could not be permitted. Adequate space was available in the fenced area for all the FRMAC vehicles, but the vehicles were all placed closely together.

8. M\&A personnel relied too heavily on floorless tents for sample receipt areas. On the first day of FRMAC-93, rain entered these tents. Contamination control could have become unmanageable. Better facilities need to be acquired for future events.

\section{F. E\&A LESSONS LEARNED}

1. Introduction. The E\&A manager must work closely with the M\&A manager to provide guidance for positioning field teams to ensure a comprehensive monitoring effort. The need to collect specific data to complete assessments must be communicated immediately so that field teams can be detailed to the locations of interest.

2. Cloud trajectory forecasts (24 hr, $48 \mathrm{hr}$, and beyond) is a highly desirable product which may be developed by one of the weather groups in the FRMAC; i.e. ARAC, NOAA, Weather Service Nuclear Support Office. These forecasts must be part of a standard package of products and are valuable to emergency planners in neighboring states who must determine if they will be impacted.

3. A problem ensued when some predictive models generated vastly different results. An attempt was made by a state representative to identify the possible cause of the discrepancy, and a request was made for confirmatory field monitoring to validate the models. The request for field measurements was not honored, or even taken to the proper decision maker. No further investigation into the cause of the discrepancy was attempted by FRMAC personnel. This caused dissatisfaction among the states, who felt that they had better model results based on field data. The process of resolving the discrepancy was inadequate. All predictive models should be evaluated on their merits and the assumptions and data used for the prediction including the 
relationship to PAGs. When there is no difference in the base data or in the assumptions, confirmatory monitoring is the preferred path for resolution.

4. The proliferation of radiological dispersion models was expected. FRMAC strongly encourages the LFA, states, utility, DOE contractors, and other federal agencies to work together. The E\&A Manager must take a more proactive position in the decision-making process to ensure that the model used is selected on a variety of scientific base. However, groups like LLNL and NOAA should consider combining their research and development efforts which would take advantage of each others' strengths.

5. The LFA personnel in the E\&A group were invaluable. They understood the facility, the Response Technical Manual ${ }^{2}$ used for accident analysis, and the planning in place.

\section{G. DATA MANAGEMENT LESSONS LEARNED}

1. Introduction. It was a difficult task to keep up with the enormous amounts of data being generated during the exercise (field team, AMS, and lab data, etc.). Two commercial size photocopy machines were used to make the required number of copies of field and laboratory data. During Days 2 and 3, more than 17,000 copies were made on these two machines. The number of copies made is an indication of the magnitude of the task of data management.

2. In the quest to ensure that only the highest quality data be passed on to the states and LFA, the FRMAC has developed quality assurance (QA) procedures to validate the information that is received from the field teams. The procedures became too restrictive when field data were not able to be quickly given to the state representatives in the FRMAC, for the sake of QA. Towards the end of the second day, a command decision was made to circumvent the QA process and give the raw data directly to the states. This change in data routing was very effective in reassuring the fact that the FRMAC is there to support the states. All FRMAC participants must have

'Response Technical Manual, NUREG/BR-0150, Vol. 1 Rev. 3, U. S. Nuclear Regulatory Commussion, Washington D.C. (1993) 
access to data in whatever condition it is available with the caveat that it must be taken in the context of its analysis and dealt with accordingly.

3. There was an over dependance on the data processing within the FRMAC. Although some technical problems can be expected during the setup and the initial hours of the FRMAC, these problems will eventually be corrected. It is important to have a bypass system for data when technical problems occur. To only have one identified pathway for the flow and distribution of data could result in a logjam of data.

4. The FRMAC Data Center's ability to quickly enter data into the database was hindered by field team data sheets that contained information which was not in the expected format. The database program had to be modified to accept the data, which caused a delay in processing the field data. The format for data reporting should be agreed upon between the Data Center and the M\&A group to prevent this problem from occurring in the future.

5. The fields in the database, when displayed on the terminal, should be arranged to mirror the field monitoring sheets. This will make it easier for data entry to locate the correct information and quickly process the data.

6. The database should prepare hourly reports of the data received. These reports should be routinely distributed to all groups.

\section{H. HEALTH AND SAFETY (H\&S) LESSONS LEARNED}

1. Introduction. H\&S operations within FRMAC need greater involvement and oversight. Virtually, all FRMAC operations should be cleared through H\&S prior to implementation. This is especially important during early FRMAC setup, establishment of headline operations, and all issues relating to personnel safety.

2. An H\&S briefing covering general and area-specific safety concerns must be given to FRMAC responders during the initial orientation. An H\&S field safety briefing should also be given to field monitors before they are dispatched from the FRMAC. Because of time limitations, the H\&S Manager at FRMAC-93 did not have the opportunity to deliver a comprehensive safety briefing to the exercise participants. 
3. A separate area, identified with a large red cross, should be designated as the area for medical services for FRMAC staff. The FRMAC must always have emergency medical services available which are commensurate to the size and nature of the response, and the availability of local services.

4. H\&S personnel had the dual responsibility of ensuring that actual (real world) safety concerns were addressed while trying to address exercise safety concerns. Some instances occurred when actual safety problems were not corrected because as players, H\&S felt that they had no control over the situation. Actual safety concerns must take priority over any exercise or training event.

5. Additionally, FRMAC H\&S oversight must function as the model for all FRMAC participants and the radiation monitoring and sampling community at large. This must encompass the entire FRMAC operation: within the FRMAC facility, field monitoring, headline, sample control and analysis, and the final disposition of contaminated samples and materials.

6. The headline was placed immediately adjacent to the electrical generator for the FRMAC equipment, which could have resulted in a contamination problem. The headline did not make use of a natural barrier in the compound and should have been more removed from the FRMAC building.

7. Visitor, controller, evaluator, and other nonplayer access to mobile labs became a problem on both exercise days. The H\&S Division must control access to the labs.

\section{FRMAC RESPONSE LESSONS LEARNED}

1. Introduction. It became readily apparent that the FRMAC staff did not fully implement its mission to support the state and LFA. FRMAC management needed to communicate its preconceptions and intentions at the earliest stage and follow up to assure that the states and LFA were satisfied with FRMAC staff interactions and support during every phase of operations. It took a boiling point to surface the failure in this area and assure that corrective actions were taken.

2. FRMAC needs to develop a standard briefing package that emphasizes integration of state staff and resources. This alone would improve operations enormously. The briefing should be the initial activity that FRMAC undertakes, possibly as part of the Advance Party meeting. FRMAC does not have a 
procedure that calls for briefing the participants on FRMAC operations early in a response. In this instance, the states of Nebraska and lowa had been trained on FRMAC operations, but had not been exposed to the actual setup and organizational structure of the FRMAC. If there were an accident tomorrow in a state that had not received the training, that state would be at an even greater disadvantage.

3. The exercise began with the states and LFA isolated behind the psychological barriers presented by the setup (curtains). It appeared as though the FRMAC staff was on one side while the federal liaison staff, states, and LFA were on the other. In addition, the FRMAC Director was isolated behind four curtain walls which contributed to the isolation factor. The curtains were intended to provide privacy to the key decision makers, but unfortunately had a negative effect.

4. The FRMAC organization is much too bureaucratic to be efficient. Consideration needs to be given to eliminating or modifying the duties of the Manager for Liaison. The position became a bottleneck for addressing state and LFA priorities and the FRMAC Director became isolated.

5. FRMAC Advance Party procedures should detail the protocol for the RAPFRMAC Advance Party and state interface meeting along with the expected outcome of producing a prioritized monitoring and sampling strategy. OPPD took the lead for facilitating the discussion. This appeared natural due to the fact that the meeting took place in the EOF.

6. The initial coordinating meetings between the federal and state representatives are of great importance in developing the long-term relationships within the FRMAC. The RAP, FRMAC Advance Party, and state interfaces should be exercised more often.

\section{J. TRAINING LESSONS LEARNED}

1. A series of FRMAC drills needs to be planned and completed which addresses specific areas of FRMAC operations. Detailed procedures and an implementation plan need to be developed to ensure that all FRMAC levels are adequately prepared.

2. The use of experienced coaches to provide on-the-job training for new managers did not appear to provide adequate training. Conceptually, this may have appeared to be the most effective method to train future managers, but 
in practice the plan fell short. This may be due in large part to inadequate instructions to coaches prior to the conduct of the exercise, and, as stated previously, the process of free play with coaching needs to be fully understood by the coaching staff and controllers.

3. Classroom training should be used to train new personnel on FRMAC policies, procedures, structure, and organization. This may be enhanced by the use of tabletop scenarios or mini-exercises at several levels. Only trained personnel should be placed in key positions--too much is invested in exercises and too much is at stake during an actual response to have inadequately trained managers and technicians.

4. Position descriptions and supporting procedures need to be fine tuned for each function within the FRMAC. Internal FRMAC and state outreach training should incorporate the use the position descriptions and procedures. The liaisons to the states need to be trained on FRMAC and the state policies and procedures.

\section{K. ORGANIZATIONAL CHANGES}

1. An evaluation of the FRMAC organizational structure used during the exercise identified several necessary changes. These changes are required to ensure that state representation within the FRMAC is supported at the highest levels. The following changes to the FRMAC organization, in response to FRMAC-93, have been or are being implemented:

a. The key state and LFA representatives will be collocated with the FRMAC Director to ensure that the decision making process reflects that needs of the states. The Manager for Technical Liaison will no longer have the responsibility to serve as the interface between the Director and the states. This position will be eliminated and the other responsibilities of this position will be absorbed by the Deputy for Liaison.

b. The FRMAC Organizational Chart in the Operations Plan will clearly identify the areas in the FRMAC where state representation is required or desired.

c. The FRMAC Coordinator position will be renamed Assistant Deputy for Operations. The position description needs to reflect an increase in the responsibilities, especially in providing one-on-one assistance to the states and LFA in the area of FRMAC operations. 
d. The title FRMAC "Chief of Staff" will be changed to "Deputy FRMAC Director." Although this is only a change in title, it more accurately describes the function of the second in command.

e. A deputy will be assigned to each FRMAC manager. The deputy must be thoroughly familiar with the FRMAC operations to allow for continuity of operations. When available, state representatives will serve as advisors to the FRMAC managers.

f. Special staff will be reduced in size. Meteorological Operations will be moved under E\&A and joined with Atmospheric Predictions.

g. Medical will be moved to $H \& S$ to adequately reflect its role of serving FRMAC workers. 


\section{SUMMARY}

In summary, FRMAC-93 met its objectives in exercising the technical component of the FRERP for response to a radiological incident at a commercial nuclear power plant. It demonstrated the need for further work in assuring that the needs of the state and local response organizations, in addition to the LFA are better integrated and incorporated into FRMAC operations.

Both the states of lowa and Nebraska expressed concern that on the first full day of FRMAC operations, that FRMAC management did not pay sufficient attention to state and local priorities and needs. However, this may have been partially due to the lack of development of a prioritized monitoring and sampling strategy during, or immediately following, the Advance Party meeting.

The flow of data within the FRMAC was slow, and as a result, the states did not feel as if the protection of the public was being adequately served by collocating operations within the FRMAC. Following a session at the end of Day 2 that addressed the states and LFA concerns, FRMAC operations improved to the point at which the confidence of state (and other federal responders) in FRMAC support capabilities was restored. On Day 3, state technical staff were better integrated into routine FRMAC operations, and state and federal decision makers were routinely consulted as to their priorities and desires in determining FRMAC efforts for field sampling and confirmatory measurements to ensure that the health and safety of the public were protected.

The experiences of FRMAC-93 will be a driving force in shaping the future of federal response to a radiological emergency, especially in the FRMAC. The lessons learned during the course of the exercise are captured in this document for the benefit of all emergency response entities. The success of FRMAC-93 was due largely to the dedication and hard work of state and federal emergency response personnel who hope that a situation will never arise in which their talents will be required. 


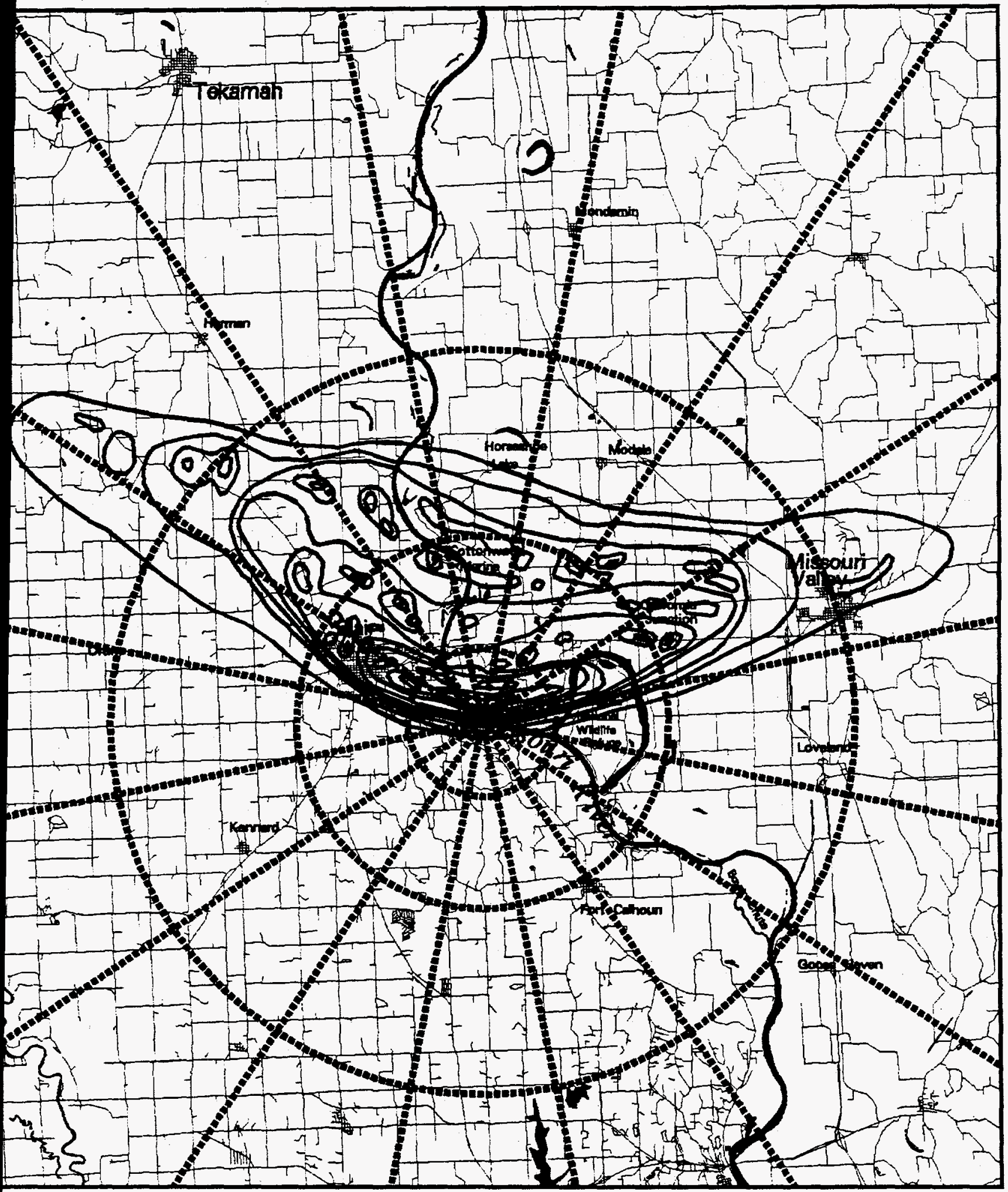

$\mathrm{le}=1: 234919$

fep dete from 1:100,000 Ther Line EPZ Grid and trpothetical plume ated by EG\&G Eneroy Messurements, ine

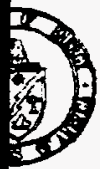

Map complled by EGsG Enerory Mescursmente, ina for the US Departmem of Enerry (DOE).

EPZ Grid $(2,5,10$ mile)

37

k Major Roads Exercise Deposition Pattern

it Calhoun Station, Nebraska - EXERCISE ONLY 


\section{LIST OF ACRONYMS} Atmospheric Release Advisory Capability Evaluation and Assessment (FRMAC) Emergency Operations Center (State)

EOF Emergency Operations Facility (Utility) Federal Bureau of Investigation Federal Coordinating Officer Federal Emergency Management Agency Federal Field Exercise Federal Radiological Emergency Response Plan FRMAC Federal Radiological Monitoring and Assessment Center GIS Geographic Information System GPS Global Positioning System H\&S Health and Safety (FRMAC) HHS Health and Human Services JIC Joint Information Center LLNL Lawrence Livermore National Laboratory Monitoring and Analysis (FRMAC) MCG Master Control Group 
NOAA

National Oceanic and Atmospheric Administration

NRC Nuclear Regulatory Commission OPPD Omaha Public Power District

PAG Protective Action Guide

PAR Protective Action Recommendation

PAST

Protective Action Support Team QA Quality Assurance RAP Radiological Assistance Program ROC Regional Operations Center SSA Senior Scientific Advisor USDA United States Department of Agriculture WSNSO Weather Service Nuclear Support Office 


\section{SUMMARY OF CRITIQUE FORM ANALYSIS}

\section{A. FRMAC OBJECTIVES}

1. How well did we fulfill the off-site monitoring and assessment requests of the states and LFA?

Overall, the response on the first day was considered poor. The second day was better, but the response to requests was still slow and communications continued to be poor.

2. How well did we prioritize the states' requests for monitoring and data?

In general, prioritization was better the second day than the first day, but still not good. The responses indicated a big difference of opinion between FRMAC personnel and state representatives.

3. Were we successtul in providing technical support for ingestion pathway and recovery phases as requested by the states and LFA?

The general opinion was that adequate technical support was provided late in the exercise. FRMAC personnel ratings for support were higher than ratings from state personnel.

4. Did we successfully integrate the various data sets and GIS into FRMAC operations? Explain.

The majority of the critiques indicated that there were far too many GIS problems. In addition, the maps and forms brought and used by the state teams were not compatible with those used by FRMAC personnel. 
5. How well did we ensure that all data and assessment results were available to key decision makers?

The critiques indicated that most exercise players thought the system was too slow. Comments reflected a need for a single information system and less red tape.

6. Was the NRC Emergency Response Staff successfully integrated into the FRMAC organization?

The overall consensus by the players was that the NRC staff was too passive and integration was a little slow to occur.

7. How well did the NRC PAST work with the FRMAC in support of the LFA?

The exercise players thought that the support was slow in getting started. Numerous critiques reflected a complete lack of knowledge concerning what PAST is/was.

8. Were we successful in blending the States' field teams with the FRMAC M\&A teams?

The respondents felt that the state field teams were very good and that blending of teams did occur. However, standardized Standard Operating Procedures need to be developed, and the FRMAC M\&A teams should provide the states with a list of FRMAC assets.

9. Was the transition of FRMAC Management from DOE and EPA effective and seamless?

Most of the respondents thought that the transition occurred quite well. 


\section{OTHER OBJECTIVES}

1. How well did the various FRMAC to states, utility, and LFA liaisons and interfaces function?

The liaisons and interfaces were quite unsatisfactory the first day, but considerable improvement was evident on the second day.

2. Were the documented FRMAC procedures effective?

The players felt that the procedures were not well enough documented and that there needs to be more interaction with the states when procedures are written.

3. Were procedural changes necessary during exercise play?

The players felt that there will always be procedural changes in fluid situations and that some adjustments were made as expected during the exercise.

4. What additional procedures need to be documented?

About one third of the respondents indicated that additional sampling, tracking, and collection procedures are needed. Another third recommended additional data flow or handling procedures. Other areas which needed better documentation included procedures for integrating the states and FRMAC, and procedures for handling contaminated samples. Some thought that all procedures need to be reviewed.

5. Were necessary resources provided to you and/or to your group?

Most respondents felt that the necessary resources were made available. A supply room with office supplies should have been made available. More GIS terminals and GIS reference materials were also needed. 


\section{Were physical facilities satisfactory?}

Although the majority of the respondents were satisfied, some stated that it was too hot and humid in the facilities. There were also some comments concerning too many people around the Headline location.

\section{Was personnel management satisfactory?}

Most respondents were satisfied with the personnel management. The players felt that the data center management and chain of command were weak. They also felt that status briefings should have been given on a recurring basis.

\section{ADDITIONAL TOPICS}

A sampling of comments provided by the exercise players follows:

1. Deposition maps should have been scaled.

2. A layout of the FRMAC should have been posted.

3. Personnel in the data center should have been briefed on their roles as team members.

4. State and FRMAC personnel did not work well together. State personnel felt they were left out of too much of the data flow and decision making.

5. GPS units need to be in a common format.

6. There were too many controllers, and controller instructions to the players were not always clear.

7. The Headline area had many problems. Better security and physical barriers were needed and would have alleviated some of the difficulties.

8. State personnel did not receive adequate training on FRMAC equipment.

9. Roles and positions were not clearly defined. Detailed standard operating procedures and a much better designation of responsibilities are badly needed.

10. The sample collection and measurement protocol was unsatisfactory. 
11. There were too many people on the radio net.

12. At times, conflicting directions were received from different managers. 


\title{
DRAFT DOE-EPA TRANSFER AGREEMENT
}

\author{
DRAFT: DO NOT QUOTE OR CITE
}

\section{FEDERAL RADIOLOGICAL MONITORING AND ASSESSMENT CENTER (FRMAC) TRANSFER PROCEDURE}

Purpose. The purpose of this procedure is to outline the framework for transfer of responsibility for operation of the FRMAC from the DOE to the EPA. Because each radiological incident will be unique, the DOE FRMAC Director and Senior EPA Official will have to use their experience and judgement in determining when to initiate the transfer. This procedure addresses those items identified in the July 16, 1991, draft of the FRERP as prerequisites for transferring FRMAC control.

1. Applicability. This procedure applies to all radiological incidents where a FRMAC has been established and there is a recognized need for intermediate and/or long term monitoring.

III. References
A. FRERP, Draft Revision, July 16, 1991.
B. EPA Radiological Emergency Response Plan, Draft Revision, December 15, 1993.
C. FRMAC, Operations Plan, Management Overview, Draft, September 1992.
D. EPA Radiological Emergency Response Plan, Implementing Procedure- Number 2, Radiological Emergency Response Training Procedure, Draft, May 10, 1993.

IV. Transfer Requirements.

The DOE FRMAC Director will work closely with the Senior EPA Official to facilitate a smooth transition of the federal radiological monitoring and assessment coordination responsibility to EPA at a mutually agreeable time and after consultation with their Headquarters, the States, and the LFA. Although it is difficult to specify in advance when the transfer of this coordination responsibility would occur, certain conditions are intended to be met prior to this transfer. These conditions include the following: 
A. The immediate emergency condition has been stabilized and off-site releases of radioactive materials have ceased, and there is little or no potential for further unintentional off-site releases. This will be verified by the Senior EPA Official with the LFA and the party responsible for the incident (e.g., the utility if a power plant accident).

B. The off-site radiological conditions have been documented and their consequences have been assessed. The EPA Data and Dose Assessment Manager will verify with the DOE FRMAC Manager for Evaluation and Assessment that all data has been documented according to the FRMAC Archival Procedures.

C. A draft long-range monitoring plan has been developed in conjunction with the affected states and federal agencies with statutory responsibilities. This will be coordinated between the EPA Field Monitoring Manager, DOE FRMAC Manager for Monitoring and Analysis, and the Senior State representative responsible for off-site monitoring.

D. EPA has received adequate assurances from the other federal agencies that they will commit the required resources, personnel, and funds for the duration of the federal response. This will be coordinated between the Office Director-Office of Radiation and Indoor Air, other affected federal agencies, LFA, the Senior EPA Official, and the DOE FRMAC Director.

After this transfer, EPA will coordinate federal radiological monitoring and assessment activities. Other participating agencies will be responsible for coordinating their monitoring activities through the EPA FRMAC Director as long as the federal agency response continues. 


\section{DRAFT}

FEDERAL RADIOLOGICAL MONITORING AND ASSESSMENT CENTER TRANSFER SIGN-OFF

will be the responsibility of the DOE FRMAC Director and the Senior EPA Official to nsure that the following conditions have been satisfied and the appropriate concurrences btained prior to effecting transfer of operational control of the FRMAC from DOE to EPA.

\section{ONDITIONS}

A. The immediate emergency condition has been stabilized and off-site releases of radioactive materials have ceased, and there is little or no potential for further unintentional off-site releases.

B. The off-site radiological conditions have been documented and their consequences have been assessed.

C. A draft long-range monitoring plan has been developed in conjunction with the affected states and federal agencies with statutory responsibilities.

D. EPA has received adequate assurances from the other federal agencies that they will commit the required resources, personnel, and funds for the duration of their federal response.

\section{DONCURRENCES}

DOE/HQ

EPA $H Q$

State NB

State IA

LFA
Concurrence from

Concurrence from

Concurrence from

Concurrence from

Concurrence from
Date/Time

Date/Time

Date/Time

Date/Time

Date/Time 